\title{
Health-related quality of life in Norwegian adolescents living with chronic fatigue syndrome
}

\author{
Wenche Ann Similä ${ }^{1,2^{*}}$ (D), Vidar Halsteinli ${ }^{3,4}$, Ingrid B. Helland ${ }^{5}$, Christer Suvatne ${ }^{1}$, Hanna Elmi ${ }^{5}$ and \\ Torstein Baade $R \emptyset^{1,2}$
}

\begin{abstract}
Purpose: The primary aim was to measure health related quality of life (HRQoL) in a Norwegian cohort of adolescents with Chronic Fatigue Syndrome (CFS/ME). A secondary aim was to identify factors before diagnosis, at time of diagnosis and after diagnosis that were associated with HRQoL.

Methods: In this cross-sectional population-based study, HRQoL was measured by Pediatric Quality of Life Inventory ${ }^{\mathrm{TM}}$ Generic Core scale version 4.0 (PedsQL4.0) in 63 adolescents with CFS/ME. In addition, fatigue was measured by PedsQL Multidimensional Fatigue scale (PedsQL-MFS), depressive symptoms were measured by the Short Mood and Feelings Questionnaire (SMFQ), and disruption in school activities was measured by The De Paul Pediatric Health Questionnaire (DPHQ-N). Data were also collected from medical records and patient interviews.

Results: Age at diagnosis was 15 (2) years (mean (SD)), and four out of five participants were female. Time from diagnosis to reply was 39 (22) months. Adolescents with CFS/ME reported PedsQL4.0 score 50 (17), and boys reported a better score than girls (64 vs $47,95 \%$ Confidence Interval (CI) for difference $(-27 ;-6)$ ). There were positive associations between overall HRQOL and support from a schoolteacher, school attendance or participation in leisure activities. There were negative associations between overall HRQoL and delayed school progression, having been to rehabilitation stay and depressive symptoms.

Conclusion: HRQoL in adolescents diagnosed with CFS/ME was low. The associations between reported HRQoL, healthcare previously provided, support from a schoolteacher, school attendance and participation in leisure activity may provide information of value when developing refined strategies for healthcare among adolescents with CFS/ ME. Possible causal relationships must however be explored in future studies.
\end{abstract}

Keywords: Adolescent, Adolescent health, Chronic fatigue syndrome, Quality of life

\footnotetext{
* Correspondence: Wenche.a.simila@ntnu.no

${ }^{1}$ Children's Clinic, St. Olavs Hospital, Trondheim, Norway

${ }^{2}$ Department of Clinical and Molecular Medicine, Norwegian University of Science and Technology, N-7489 Trondheim, Norway

Full list of author information is available at the end of the article
}

(C) The Author(s). 2020 Open Access This article is licensed under a Creative Commons Attribution 4.0 International License, which permits use, sharing, adaptation, distribution and reproduction in any medium or format, as long as you give appropriate credit to the original author(s) and the source, provide a link to the Creative Commons licence, and indicate if changes were made. The images or other third party material in this article are included in the article's Creative Commons licence, unless indicated otherwise in a credit line to the material. If material is not included in the article's Creative Commons licence and your intended use is not permitted by statutory regulation or exceeds the permitted use, you will need to obtain permission directly from the copyright holder. To view a copy of this licence, visit http://creativecommons.org/licenses/by/4.0/ The Creative Commons Public Domain Dedication waiver (http://creativecommons.org/publicdomain/zero/1.0/) applies to the data made available in this article, unless otherwise stated in a credit line to the data. 


\section{Introduction}

Chronic fatigue syndrome (CFS) is characterized by overwhelming and severe disabling fatigue, and loss of physical and mental endurance [1]. The condition is also cited as Myalgic Encephalomyelitis (ME) to conceptualize a specific neuroimmunological condition [2]. A main characteristic of the disease is post exertional malaise (PEM). Other symptoms include orthostatic intolerance and other signs of autonomic dysfunctions, cognitive impairment, unrefreshing sleep, sore throat, headache, dizziness, heat and cold intolerance, muscular and abdominal pain, nausea, vomiting and mood disturbances [3-6]. CFS/ME occurs more frequently in the age groups $11-19$ and 30-39 and is $3-4$ times more common in girls than boys. In Norway $0,1-1,0 \%$ adolescents are affected $[1,7,8]$. Adolescents CFS/ME starts with an acute or gradual, infectious or non - infectious onset. Establishment of the diagnosis is frequently delayed, with the period from start of symptoms to diagnosis varying from 5 to 17 months $[3,9]$. The CFS/ ME disease course is often measured in years, and it is common to experience recurring improvement and relapses [1]. Among adolescents, CFS/ME is the most common cause of long-term absence from school [4, 10-13].

Previous studies have shown that CFS/ME severely impact health-related quality of life (HRQoL) [1]. Typically, adolescents with CFS/ME report lower HRQoL than adolescents diagnosed with other chronic health conditions like ADHD, cancer or cerebral palsy [14-17]. In an earlier Norwegian study of HRQoL among adolescents with CFS/ME, patients scored 49 whereas healthy controls scored 93 on a $0-100$ generic HRQoL scale based on PedsQL 4.0 [16].

CFS/ME patients need care from primary health care and schools. Because of the complexity and severity of the illness, specialized care from personnel experienced with CFS/ME is often warranted, but frequently not available [1]. Despite substantial efforts from health care and schools, we still lack knowledge about effective strategies to improve disease outcome and HRQoL. The main aim of this study was to measure HRQoL in adolescents with CFS/ME, and a secondary aim was to identify factors before diagnosis, at diagnosis and after diagnosis positively or negatively associated with HRQoL.

\section{Methods}

\section{Study design}

A cross-sectional, population-based study of HRQoL in adolescents diagnosed with CFS/ME.

\section{Study population}

\section{CFS/ME adolescent patients}

Adolescents diagnosed with CFS/ME at St. Olavs or Oslo University Hospitals in Norway with age 12-18 at the time of diagnosis were invited by mail to participate.
Participants were asked to complete a questionnaire and to attend an interview. Invitation was sent between $\mathrm{Au}$ gust 2017 and January 2018, and time since diagnosis varied from 1 to 118 months. Of 168 invited, 86 (51,2\%) agreed to participate, and $63(37,5 \%)$ returned completed questionnaires. All participants were diagnosed with $\mathrm{G}$ 93.3 CFS/ME according to Jason diagnostic criteria [5], and the diagnosis was verified by an independent evaluation of medical records. Exclusion criteria were not being able to read Norwegian or reply to questionnaires or participate in interview. No one was excluded according to these criteria. Data collection from questionnaires, interviews and medical records finished in June 2018.

\section{Measures \\ PedsQL generic Core scale}

The Norwegian version of Pediatric Quality of Life Inventory $^{\text {Tm }}$ Generic Core scale version 4.0 (PedsQL4.0) was used to measure HRQoL. PedsQL4.0 is a 23-item generic questionnaire developed to measure $\mathrm{HRQ}$ LL in both healthy and acute or chronic ill children and adolescents [18]. A young adult version was used for ages 18-22. The PedsQL4.0 provides a generic sum score and subscale scores; Physical functioning (8 items) and Psychosocial functioning as total of: Emotional functioning (5 items), Social functioning (5 items) and School functioning (5 items). Participants were asked to rate each item during the last month on a Likert scale from 0 (never a problem) to 4 (almost always a problem). The items were reversely scored and linearly transformed on a scale ranging from 0 to $100(0=100,1=75,2=50$, $3=25,4=0)$. Higher scores indicate better HRQoL [18].

\section{PedsQL multidimensional fatigue scale}

The Pediatric Quality of Life Inventory ${ }^{\mathrm{Tm}}$ Multidimensional Fatigue scale (PedsQL-MFS) was used to measure fatigue severity [19]. PedsQL-MFS is a generic scale with 18 items, and with subscale scores for three domains; general fatigue (6 items), fatigue related to sleep/rest (6 items) and cognitive fatigue (6 items). The response scale is the same as for PedsQL4.0. Higher scores indicate less fatigue.

\section{Short mood and feelings questionnaire}

The Short Mood and Feelings Questionnaire (SMFQ) is a self-report-form measuring depressive symptoms in children and adolescents. Thirteen items collectively describe depressive symptoms, covering for symptoms specific for major depression in DSM-IV. The SMFQ items have three reply options; "True" $=2$, "Sometimes" $=1$, "Not true" $=0$ referring to the last 2 weeks with a sum score from 0 to 26 . A sum score of 11 or higher indicates depressive symptoms which possibly require treatment [20]. 
De Paul pediatric health questionnaire - Norwegian version The De Paul Pediatric Health Questionnaire (DPHQ-N) for children and adolescents was translated to Norwegian by The Norwegian National Advisory Unit on CFS/ME. Translation and re-translation was performed according to EORTC [21], re-translated by one and accepted by original author. This is a self-report questionnaire for children ages 10-17 in three parts; 1) demographic data, 2) a list of CFS/ME-related symptoms from the current CFS/ ME criteria according to Jason, with symptoms rated in frequency $(0=$ never, $1=$ almost never, $2=$ half the time, $3=$ almost always, $4=$ always $)$, and in severity $(0=$ no problem, 1 = small problem, $2=$ moderate problem, $3=$ big problem, 4 = very big problem), and 3) experience of disruption in school activities or performance due to fatigue or cognitive difficulties $[5,22,23]$.

\section{Data from medical records and additional interviews with patients}

Data from medical records were collected using a semistructured guide developed by the research group. One pediatrician from each hospital and one psychiatrist from St. Olavs hospital used the same guide when collecting data from diagnostic evaluation in medical records. Supplementary data providing information of contact with primary health care personnel and schools were collected directly from the participants via a six to 7 minute telephone interview using an interview guide with the same questions for all participants.

\section{Statistical analyses}

First, we examined the study population characteristics. Then we examined HRQoL, fatigue and depressive symptoms in relation to study population characteristics. Continuous data (age, duration of fatigue, HRQoL, fatigue severity and depressive symptom scores) are presented as mean (SD), Median (Q1-Q3), and 95\% confidence intervals (CI) where appropriate. Correlations between HRQoL, fatigue severity and depressive symptoms are presented as Pearson's correlation coefficients. Categorical data (gender, recovered/not recovered, delayed school progression and participation in leisure activities) are presented as numbers and percentages.

Next we examined a wide spectrum of factors related to the periods before diagnostic evaluation, through diagnostic evaluation and after diagnosis in relation to HRQoL (PedsQL 4.0). For these dichotomous factors two-sided independent sample t-test were used to assess differences. Complete results are presented in Supplemental Tables 1, 2, 3, 4, 5, 6, while statistically significant variables $(5 \%$ level $)$ are presented in Table 3. Generic HRQoL scores are presented as mean (SD) plus 95\% confidence intervals (CI) for differences. For dimension scores only difference and CI are reported. These analyses were indicators for regression analysis and were not corrected for multiple testing.

Finally, we examined independent variables significantly associated with HRQoL as predictor variables in a multiple linear regression model, controlling for gender. The model included all participants with replies to dichotomous variables. Dependent variable was tested for normal distribution and outliers. Predictor variables were tested for multicollinearity. Unstandardized Beta coefficients with confidence intervals $(\mathrm{CI})$, Adjusted $\mathrm{R}^{2}$, model significance (ANOVA), F-values, $\beta$-values and $p$ values for each predictor were reported. A difference of 10 in primary outcome (HRQoL) was predetermined as clinically relevant.

Among 63 participants, 48 answered additional questions about contact with primary health care personnel and school. All statistical analyses were performed using SPSS version 23 .

\section{Ethics}

The study was approved by The Regional Ethical Committee for medical and health profession research in Norway (REK 2017/749). All participants signed an informed consent, and the study was performed according to the declaration of Helsinki. The participants were offered a consultation to explore the need for further health care.

\section{Results}

\section{Study population characteristics}

Sixty-three adolescents with CFS/ME were included in the study, with a female: male ratio of $4,2: 1$ and mean age18 years (Table 1 ). Duration of fatigue initial to diagnostic evaluation was 15 months (10-33) (median (Q1Q3)), and at the time of study enrollment 52 months (36-67) (median (Q1-Q3)). 37 (76\%) of the adolescents had a delayed school progression defined as not having completed all compulsory subjects in school at their level. Furthermore, most of the adolescents (66\%) reported no participation in leisure activities. Four adolescents had recovered after 6, 12 and 36 months, respectively (one unknown) (Table 2).

Generic PedsQL4.0 score for all participants in this study was 50 (17) (mean (SD)) (Table 1). The subscale scores were lowest for the domain school functioning and highest for social functioning. Overall PedsQL-MFS score was 36 (19). The domain general fatigue had the lowest score. There was a strong correlation between generic PedsQL4.0 and overall PedsQL-MFS scores (Pearson's $r=.861, p<.001)$. The SMFQ sum score was 7 (5) (mean (SD)), whereas $27 \%$ of the participants scored 11 or higher, suggesting a possible treatmentrequiring depression. The correlation between SMFQ 
Table 1 Patient characteristics and overall results from PedsQL 4.0, PedsQL-MFS and SMFQ

\begin{tabular}{|c|c|c|c|c|}
\hline & $\mathrm{N}$ & $\%$ & Mean (SD) & Median (Q1-Q3) \\
\hline Gender (Female / Male / Undetermined) & $50 / 12 / 1$ & $79 / 19 / 2$ & & \\
\hline Age at time of enrolment & 63 & & $18(2)$ & \\
\hline Duration of fatigue before diagnostic evaluation (months) a) & 48 & & & $15(10-33)$ \\
\hline Duration of fatigue at time of enrolment (months) & 59 & & & $52(36-67)$ \\
\hline Recovered from CFS/ME (yes/no) & $4 / 58$ & $6 / 94$ & & \\
\hline Delayed school progression (yes/no) & $37 / 12$ & $76 / 24$ & & \\
\hline Participation in leisure activities (yes/no) & $21 / 41$ & $34 / 66$ & & \\
\hline \multicolumn{5}{|l|}{ PedsQL4.0 } \\
\hline Overall HRQoL score (b)(c) & 63 & & $50(17)$ & \\
\hline Sub-scale scores: Social functioning & 63 & & $67(16)$ & \\
\hline Emotional functioning & 63 & & $56(20)$ & \\
\hline Physical functioning & 63 & & $42(25)$ & \\
\hline School functioning & 58 & & $41(21)$ & \\
\hline Psychosocial functioning & 63 & & $55(16)$ & \\
\hline \multicolumn{5}{|l|}{ PedsQL-MFS } \\
\hline Overall Fatigue score (b) & 62 & & $36(19)$ & \\
\hline Sub-scale scores: Cognitive fatigue & 62 & & $41(25)$ & \\
\hline Fatigue related to sleep/rest & 62 & & $36(19)$ & \\
\hline General fatigue & 62 & & $32(23)$ & \\
\hline SMFQ (13 items) Sum score (c) & 63 & & $7(5)$ & \\
\hline Score $<11 / 11$ or higher & $46 / 17$ & $73 / 27$ & & \\
\hline
\end{tabular}

a) Not available data from 15 participants, b) Pearson's correlation $=.861, p<.001$ between generic PedsQL4.0 and overall PedsQL-MFS, c) Pearson's correlation $=-.544, p<.001$ between generic PedsQL 4.0 and SMFQ sum score

Table 2 PedsQL generic and multidimensional fatigue scales and SMFQ sum score related to patient characteristics

\begin{tabular}{|c|c|c|c|c|c|c|c|c|c|}
\hline & \multicolumn{3}{|c|}{ PedsQL Generic scale (23 items) } & \multicolumn{3}{|c|}{ PedsQL Multidimensional Fatigue scale (18 items) } & \multicolumn{3}{|c|}{ SMFQ sum score (13 items) } \\
\hline & $N$ & Mean (SD) & $95 \% \mathrm{Cl}$ for diff & $N$ & Mean (SD) & $95 \% \mathrm{Cl}$ for diff & $\mathrm{N}$ & Mean (SD) & $95 \% \mathrm{Cl}$ for diff \\
\hline \multicolumn{10}{|l|}{ Gender } \\
\hline Girls & 50 & $47(16)$ & $(-27 ;-6)$ & 49 & $33(16)$ & $(-30 ;-7)$ & 50 & $8(5)$ & $(2-6)$ \\
\hline Boys & 12 & $64(20)$ & & 12 & $51(24)$ & & 12 & $4(3)$ & \\
\hline \multicolumn{10}{|l|}{ Age: } \\
\hline$<16$ & 10 & $57(17)$ & $(-4-20)$ & 10 & $46(13)$ & $(-2 ;-24)$ & 10 & $6(3)$ & $(-4-0)$ \\
\hline $16+$ & 53 & $49(17)$ & & 52 & $34(20)$ & & 53 & $8(6)$ & \\
\hline \multicolumn{10}{|l|}{ Status at response time } \\
\hline Not recovered from CFS/ME & 58 & $48(16)$ & $(19-51)$ & 57 & $33(16)$ & $(-61 ;-28)$ & 58 & $8(5)$ & $(0-10)$ \\
\hline Recovered from CFS/ME & 4 & $83(13)$ & & 4 & $78(15)$ & & 4 & $3(4)$ & \\
\hline \multicolumn{10}{|c|}{ Is your school progression delayed } \\
\hline Yes & 37 & $49(16)$ & $(-27 ;-4)$ & 37 & $34(19)$ & $(-31 ;-6)$ & 37 & $8(5)$ & $(-1-6)$ \\
\hline No & 12 & $65(18)$ & & 12 & $52(21)$ & & 12 & $5(6)$ & \\
\hline \multicolumn{10}{|c|}{ School attendance before diagnosis } \\
\hline$<50 \%$ & 39 & $50(18)$ & $(-25-2)$ & 38 & $36(19)$ & $(-29-1)$ & 39 & $8(5)$ & $(-2-6)$ \\
\hline $50 \%$ or more & 9 & $61(21)$ & & 9 & $50(25)$ & & 9 & $6(5)$ & \\
\hline \multicolumn{10}{|c|}{ Do you participate in leisure activity } \\
\hline Yes & 21 & $59(17)$ & $(4-22)$ & 21 & $46(19)$ & $(5-24)$ & 21 & $6(4)$ & $(-5-0)$ \\
\hline No & 41 & $46(16)$ & & 40 & 31 (18) & & 41 & $9(5)$ & \\
\hline
\end{tabular}

Two-sided Independent Samples T-test. Difference in N is due to one undetermined which gender, and that participation with questionnaire was higher than participation in interview 
and generic PedsQL4.0 score showed moderate to strong negative correlation $(r=-.544, p<.001)$.

There was no correlation between duration of fatigue at time of study enrolment and overall score of HRQoL, fatigue level or depressive symptoms (Fig. 1). CFS/ME diagnosis for all participants were confirmed from medical records. In DPHQ-N question 59 IV "Worst symptom right now" there was an option to mark "I am not ill" - 4 participants marked this option at the time of reply. This was recorded as recovery from CFS/ME. Adolescents recovered from CFS/ME reported higher HRQoL than those who had not recovered (83 vs. 48, $p<.001$ ) (Table 2).

\section{HRQoL, fatigue and depressive symptoms versus study population characteristics}

There was a significant gender difference in generic PedsQL4.0 score where girls scored significantly lower than boys (47 vs $64, p=.003$ ). In subscale scores, girls scored lower than boys for all dimensions (data not shown). There was also a significant gender difference in PedsQL-MFS score where girls scored lower than boys, and a similar result was found in the SMFQ score (Table 2).

School attendance, delayed school progression or participation in leisure activities were not statistically significant associated with SMFQ scores (Table 2). However, both generic PedsQL4.0 and overall PedsQLMFS scores differed between adolescents having or not having participated in leisure activities or delayed school progression, with higher scores for the adolescents who were able to participate in leisure activities and adolescents with a normal school progression. School attendance before diagnostic evaluation showed a similar trend when setting the cut-off at 50\% school attendance, although not attaining statistical significance.

\section{HRQoL versus selected factors before diagnosis, by the time of diagnosis or after diagnosis}

To further explore factors positively or negatively associated with HRQoL, 34 variables collected from patients and medical records were selected and divided into three groups; before diagnosis, by the time of diagnosis and after diagnosis. Factors significantly associated with generic PedsQL4.0 or subscale scores are shown in Table 3.

Looking at the possible association between HRQoL and factors being present before the CFS/ ME diagnose, we found that school attendance $<50 \%$ or using medications were associated with lower HRQoL in PedsQL subscales, but not with generic PedsQL4.0.

All adolescents had a physician involved in diagnostic evaluation. Beyond that, there were differences regarding the type of health personnel involved. Our analyses show that when either an occupational therapist, a physical therapist or a clinical nutritionist were involved, this was positively associated with the PedsQL4.0 subscale emotional functioning, but not with other subscales or generic score.

For the period after diagnosis, we found four factors associated with HRQoL. Support from schoolteacher was positively associated with generic PedsQL 4.0 (55 vs $41, \mathrm{CI}(0.08-29))$, and with the subscale scores for emotional and psychosocial functioning. Participation in leisure activity was positively associated with generic PedsQL4.0 (59 vs 46, CI (4-22)) and with the subscale scores for physical, social, school and psychosocial functioning. Been to rehabilitation stay was

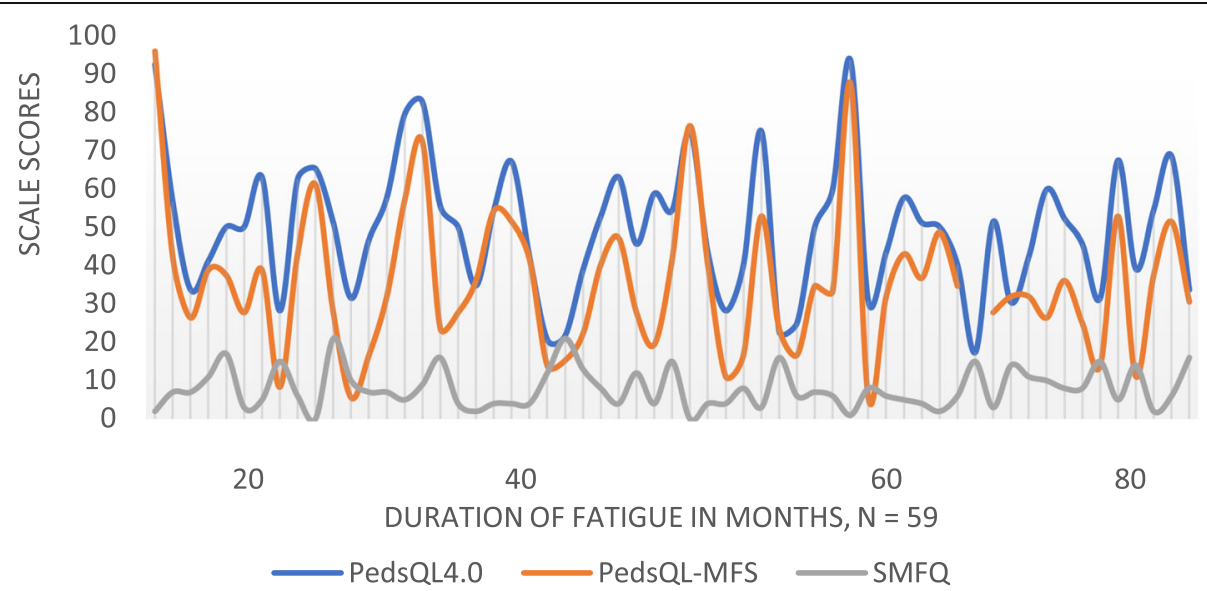

Fig. $1 \mathrm{HRQOL-}$, Fatigue- and SMFQ- scores in relation to Duration of fatigue, $n=59$. For PedsQL4.0 and PedsQL-MFS high score is better, for SMFQ low score is better 


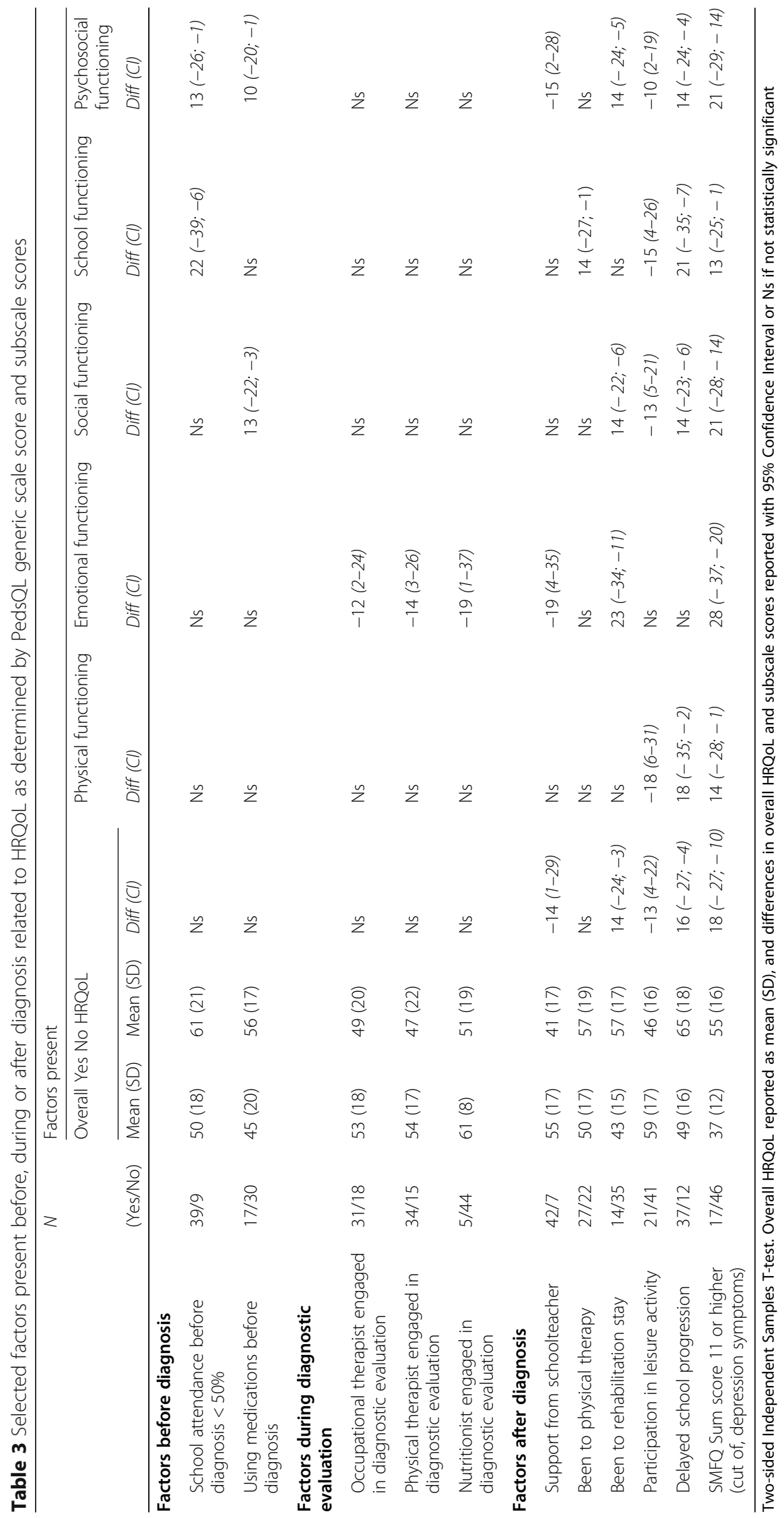


negatively associated with generic PedsQL4.0 (43 vs 57 , CI $(-24 ;-3))$ and with subscale scores for emotional, social and psychosocial functioning. Been to physical therapy was negatively associated with school functioning. Delayed school progression was negatively associated with generic PedsQL4.0 (49 vs 65, CI $(-27 ;-4))$ and with subscale scores for physical, social, school and psychosocial functioning. We also found that possible clinically significant depression (SMFQ score equal to or greater than 11) was negatively associated with generic HRQoL (CI $(-27 ;-10))$ and with all dimensions. Findings from bivariate analyses along with clinical relevance were indicators for which factors to include in the multiple regression analysis.

\section{Multivariate analysis: $\mathrm{HRQ}$ oL versus selected factors in a regression model}

Multiple linear regression analysis was performed to predict HRQoL based on the four variables from after diagnosis, identified from bivariate analyses and with the most significant positive or negative association. The four variables were considered as clinically relevant and adequate to both health care, support from school and to the loss of important activities these adolescents suffer from. Dependent variable generic PedsQL 4.0 was normally distributed. Forthy-eight participants had responded to all predictor variables. Predictor variables correlated with HRQoL (Pearson's $r>.300$ except for support from teacher $\mathrm{r}$.290) (Table 4).

The results from the multiple regression analysis confirmed the associations from bivariate analyses. The regression model was significant at the level $p=.001$, explaining $32 \%$ of the variance. Support from schoolteacher and participation in leisure activities were positively associated with HRQoL, while negative associations came from delayed school progression, and having been to a rehabilitation stay. The regression coefficient for delayed school progression was - $10(\beta-.249)$, and for support from schoolteacher 10 $(\beta$.200), indicating clinical relevance. We also looked at the multiple linear regression analysis without the four participants who reported recovery. The predictors were distributed similarly in the regression model, and with similar results.

Based on the difference in bivariate analyses between participants with and without depressive symptoms, we looked at the multiple regression analysis if excluding the group of 10 participants with depressive symptoms. With $n=38$ participants the distribution of the predictors was still the same, but with regression coefficient for delayed school progression at $-14(\beta-.378)$, and support from schoolteacher 10 ( $\beta$.162). Participation in leisure activity, $\beta .260$, and been to rehabilitation stay, $\beta$ -.143 . Hence the model explained $23 \%$ of the variance $(p=.019)$.

\section{Discussion}

The primary aim of this study was to measure HRQoL in adolescents living with CFS/ME. Overall, HRQoL in this patient group was low. Secondary aims were to identify factors before, at time of and after diagnosis, associated with HRQoL. School absence higher than 50\% before diagnostic evaluation, delayed school progression, having attended physical therapy or rehabilitation stay after diagnosis were associated with lower HRQoL. Occupational therapist, physical therapist or clinical nutritionist engaged in diagnostic evaluation were associated with higher HRQoL. After diagnosis, being supported by a schoolteacher, attending school or participating in leisure activities were associated with higher HRQoL. We found no correlation between duration of fatigue at time of enrolment and HRQoL, fatigue severity or depressive symptoms.

HRQoL in adolescents living with CFS/ME was low compared to healthy adolescents as reported by previous studies. Healthy adolescents typically scored 83 or higher, and adolescents with other chronic diseases scored from 66 to 77 [14-17]. Importantly, girls

Table 4 Multiple Linear regression - predictors to HRQOL in adolescents diagnosed with CFS/ME

\begin{tabular}{lllll}
\hline$N=48$ & Beta coefficient & $(95 \%$ Cl) & $\beta$ & .000 \\
\hline Constant & 50 & $(34-66)$ & $(-1-21)$ & .230 \\
Gender (a) & 10 & $(-3-23)$ & .200 & .079 \\
Support from schoolteacher (b)(c) & 10 & $(-21-1)$ & -.249 & .211 \\
Delayed school progression (d) & -10 & $(-2-18)$ & .051 \\
Participation in leisure activity (e) & 8 & $(-18-2)$ & .212 \\
Been to rehabilitation stay (f) & -8 & .114 \\
\hline
\end{tabular}

a) female $=0$, male $=1$ ), b) support from schoolteacher no $=0$, yes $=1$, c) support from schoolteacher,

correlation coefficient to HRQoL $.290(<.3)$. d) school delay no $=0$, yes $=, 1$, e) participate in

leisure activity no $=0$, yes $=1$, f) been to rehabilitation stay no $=0$, yes $=1$

Model summary: Adj. $R^{2} .319$, F Change 5.399, Sig (ANOVA) $p=.001$ 
scored lower than boys in both generic and dimensional PedsQL4.0 and PedsQL-MFS. Similar results were earlier found in a Norwegian study from 2015 [16], and internationally [24]. The low HRQoL scores in CFS/ME adolescents suggest a need for new strategies to improve HRQoL.

School absence higher than 50\% before diagnostic evaluation or delayed school progression were associated with lower HRQoL. Maintaining contact with school have in previous studies shown to be important $[25,26]$. CFS/ME symptoms and the subsequent reduction in activities, socializing and school delay may lead to anxiety, depressive mood and increased tension [27]. Measures to maintain school progression to improve HRQoL for adolescents with CFS/ME should be considered.

Participation in physical therapy or a rehabilitation stay were associated with lower HRQoL. Rehabilitation programs with exercise, mobilization and body awareness typically delivered from physical therapists, are earlier described as effective in reducing medium- and long-term fatigue severity in CFS/ME patients [28]. These findings seemingly conflict with our findings, i.e. that physical therapy or rehabilitation stay were associated with lower HRQoL. The lack of knowledge and disagreement about strategies to improve HRQoL in these patients might contribute to disruption in therapeutic alliances with patients and parents, and to distrust in health care personnel [29-31]. Our findings might indicate that adolescents with low HRQoL are more likely to attend or being offered a rehabilitation stay, and that a long-term plan with regularly mapping of symptoms could be most helpful for health care personnel to plan an individualized rehabilitation stay.

On the other hand, occupational therapist, physical therapist and clinical nutritionist engaged in diagnostic evaluation were associated with higher HRQoL. Occupational and physical therapists are commonly engaged in adaption of management plans after CFS/ ME diagnosis [1]. Our findings suggest engagement also in diagnostic evaluation. Engagement from nutritionists could potentially be important since approximately $10 \%$ of adolescents with CFS/ME suffer from eating-difficulties [13].

Importantly, we found that support from schoolteacher was associated with higher HRQoL. To meet responsive and caring teachers, get assistance from sympathetic counselors, and the possibility to have flexible schedules might be just as important as support and care from health care professionals [1]. The positive association between support from schoolteachers and emotional functioning may be related to prevention of depressive symptoms. The importance of meeting in small groups with peers, and cooperation between health care professionals and school is earlier described as helpful [27]. The ability of schoolteachers to support adolescents with CFS/ ME who are not present at school might improve the cohesion with school society and secondary improve HRQoL.

School attendance could result in PEM from physical, cognitive and social activity. Socialization is recommended as a priority when adolescents with CFS/ME attend school, and adjustment of the curriculum is necessary [1]. Teaching via digital tools is a strategy that potentially benefit adolescents with CFS/ME.

Participation in leisure activities was associated with higher HRQoL. Perhaps this is because the healthiest adolescents are more likely to participate in leisure activities. However, participation in leisure activities should be further studied throughout the course of CFS/ME when searching for strategies to improve HRQoL. This may decrease stigmatization of adolescents with CFS/ ME who participate in leisure activities, even if they don't manage obligatory school activity in line with healthy adolescents.

We found no correlation between duration of fatigue at time of enrolment and HRQoL, fatigue severity or depressive symptoms. Adolescents with CFS/ME are not able to do the things they want, and they suffer from loss, disruption and coping barriers [1, 26, 27, 32]. A previous study found no statistical evidence between depressive symptoms and low HRQoL [16]. Rather the duration of fatigue before diagnosis, the demanding diagnostic process, lack of medical understanding and lack of positive prognosis information, might provoke anxiety since the adolescents perceive their CFS/ME as being permanent and threatening to their future hopes and dreams [6, 10]. Previous studies emphasize how important it is that professionals involved in the diagnostic evaluation and health care of adolescents after diagnosis of CFS/ME agree about treatment and communicate consistently [29]. According to Rowe [1] "Management of CFS/ME requires careful attention.", and that the surroundings are aware and supportive in order to give the adolescents a potential to prevent depressive symptoms and gain hope of an active and productive future. To avoid increased symptoms and relapses, they need a long-term plan for health care with regularly mapping of symptoms, guidance on activity, and regularly adjustments to symptoms severity or improvement [1]. Collectively, our findings support this. 


\section{Strengths and limitations}

A strength to our study is that we explore the relationship between HRQoL and various factors especially during the period after diagnosis. Furthermore, our participants had a mean duration of fatigue close to 4 years which adds relevance to our findings. The diagnosis was verified according to the Jason criteria, and the diagnostic evaluation and health care after diagnosis at the two hospitals participating in this study are relatively uniform. A limitation to our study was a possibility to miss significant associations between HRQoL and factors before, by the time of or after diagnosis due to a small sample size. In the multiple regression analysis we only adjusted for gender, due to sample size. Bivariate analyzes were not corrected for multiple testing, and accordingly results should be cautiously interpreted. Sixtythree participants reported HRQoL with selfcompleted questionnaires, while only 48 responded to the telephone interview. This lost-to-follow-up bias resulted in exclusion of participants in the bivariate and multivariate analyses and could have been avoided by adding the questions from the telephone interview to the self-complete questionnaire. A further limitation was that patients with CFS/ME often have reduced cognitive function, and it may be difficult to remember exactly what occurred early in the disease course leading to recall-bias. Importantly, given our cross-sectional study design, it is impossible to conclude whether factors have a causal significance to HRQoL.

\section{Implications}

We still lack effective treatment of fatigue in CFS/ME patients, and despite effort from health-services and schools, HRQoL in adolescents with CFS/ME is low. A focus on strategies to improve psychosocial function, especially in relation to school, during diagnostic evaluation and after diagnosis might contribute to higher HRQoL (Fig. 2). Focus on participation in leisure activities in association to HRQoL is potentially needed to improve HRQoL and avoid stigmatization of CFS/ME adolescents. A long-term plan for health care with regularly mapping of symptoms from early stages of the disease might reveal data with importance to prevent the significant reduction of HRQoL, regarding both physical, social and emotional aspects [1]. Cooperation between schools, primary health care and hospitals when caring for adolescents with CFS/ME are of most importance.

For all patients with chronic health conditions, the goal of health care should be to restore them to the fullest health possible by improving symptom management, treatment adherence, and their ability to cope with their condition. For this reason, HRQoL may be just as important as biomedical measures when assessing patients with chronic health conditions like CFS/ME. The PedsQL4.0 is developed from the Worlds Health Organization's definition of health and is a valid instrument for this purpose [33].

\section{Conclusion}

In this cross-sectional study of adolescents with CFS/ ME we found low HRQoL. The study identified new and possibly important factors associated with HRQoL. When exploring factors before, at the time of or after diagnosis associated with HRQoL, we found that school attendance, support from a schoolteacher and participation in leisure activities were associated with higher HRQoL. We also found associations to higher emotional functioning, when occupational therapist, physical therapist and clinical nutritionist were engaged in diagnostic evaluation. On the other hand, school absence higher than 50\% before diagnostic evaluation, delayed school progression or having been to a rehabilitation stay were negatively associated with HRQoL. Early diagnosis, mapping of symptoms severity and HRQoL, maintaining school contact and early action to prevent depressive symptoms might be important to improve HRQoL in these patients. Limitations to our study design imply that future interventional studies are needed to confirm whether the identified factors can be used to improve HRQoL in adolescents with CFS/ME.

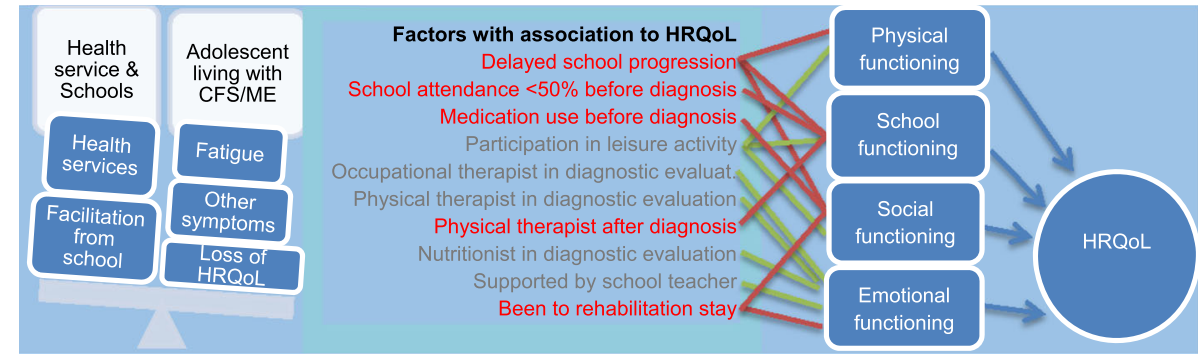

Fig. 2 Factors found with association to HRQoL in adolescents living with CFS/ME 


\section{Supplementary information}

Supplementary information accompanies this paper at https://doi.org/10. 1186/s12955-020-01430-z.

Additional file 1: Supplemental Table 1. HRQOL as measured by generic PedsQL4.0 versus selected factors before, at or after diagnosis Supplemental Table 2. Physical functioning versus selected factors before, at or after diagnosis. Supplemental Table 3. Emotional functioning versus selcted factors before, at or after diagnosis. Supplemental Table 4. Social functioning versus selected factors before, at or after diagnosis. Supplemental Table 5. School functioning versus selected factors before, at or after diagnosis. Supplemental Table 6. Psychosocial functioning versus selected factors before, at or after diagnosis.

\section{Abbreviations}

CFS/ME: Chronic fatigue syndrome/myalgic encephalomyelitis; PEM: Post exertional malaise; HRQoL: Health related quality of life; PedsQL4.0: Pediatric Quality of Life Inventory ${ }^{\mathrm{TM}}$ Generic Core scale version 4.0; PedsQLMFS: Pediatric Quality of Life Inventory ${ }^{\mathrm{TM}}$ Multidimensional Fatigue scale SMFQ: Short Mood and Feelings Questionnaire; DPHQ-N: De Paul Pediatric Health Questionnaire -Norwegian version

\section{Acknowledgements}

We thank The Norwegian Ministry of Health and Care services (HOD) and The National Competence center for Complex Symptom Disorders, St. Olavs Hospital for funding of this project. We also thank Anne Karen L. Bakken and Else Stålen for valuable input regarding study design and help with data collection. Finally, we thank the adolescents who participated in the study.

\section{Authors' contributions}

WAS collected, analyzed and interpreted the patient data. TBR supervised the project, analyses and interpretation of data. VH supervised the project, analyses and interpretation of data. IBH facilitated and supervised data collection from Oslo University Hospital. CS supervised the project and collected data from medical records. HE collected data from medical records. All authors read and approved the final manuscript.

\section{Funding}

Research relating to this article was funded by The Norwegian Ministry of Health and Care Services, St. Olavs Hospital and Norwegian University of Science and Technology.

\section{Availability of data and materials}

The dataset generated and analyzed during the current study is not public available due to ethical standards for treatment of patient data.

\section{Ethics approval and consent to participate}

All procedures performed were in accordance with the ethical standards of the national research committee (The Regional Ethical Committee for medical and health profession research in Norway, REK 2017/749). Informed consent was obtained from all individual participants included in the study.

\section{Consent for publication}

Informed consent obtained from all individual participants included consent for publication of anonymized data.

\section{Competing interests}

The authors declare that there is no competing interest.

\section{Author details}

${ }^{1}$ Children's Clinic, St. Olavs Hospital, Trondheim, Norway. ${ }^{2}$ Department of Clinical and Molecular Medicine, Norwegian University of Science and Technology, N-7489 Trondheim, Norway. ${ }^{3}$ Regional Center for Health Care Improvement (RSHU), St. Olavs Hospital, Trondheim, Norway. ${ }^{4}$ Department of Public Health and Nursing, Norwegian University of Science and Technology, Trondheim, Norway. ${ }^{5}$ Division of Pediatric and Adolescent Medicine, Oslo University Hospital, Oslo, Norway.
Received: 24 January 2020 Accepted: 2 June 2020

Published online: 05 June 2020

\section{References}

1. Rowe PC, Underhill RA, Friedman KJ, Gurwitt A, Medow MS, Schwartz MS, Speight N, Stewart JM, Vallings R, Rowe KS. Myalgic encephalomyelitis/ chronic fatigue syndrome diagnosis and Management in Young People: a primer. Front Pediatr. 2017:5:121.

2. Maes M, Twisk FN, Johnson C. Myalgic encephalomyelitis (ME), chronic fatigue syndrome (CFS), and chronic fatigue (CF) are distinguished accurately: results of supervised learning techniques applied on clinical and inflammatory data. Psychiatry Res. 2012;200:754-60.

3. Clayton EW. Beyond myalgic encephalomyelitis/chronic fatigue syndrome: an IOM report on redefining an illness. JAMA. 2015;313:1101-2.

4. Carruthers BMJA, De Meirleir KL, Peterson DL, Klimas NG, Lemer AM, Bested AC, Flor-Henry P, Joshi P, Powles ACP, Sherkey JA, van de Sande MI. Myalgic encephalomyelitis/chronic fatigue syndrome: clinical working case definition, diagnostic and treatment protocols (Canadian case definition). Chronic Fatigue Syndrome. 2003;11:7-115.

5. BD JLA, Rowe K, Van Hoof ELS, Jordan K, Lapp C, Gurwitt A, Miike T, TorresHarding S, De Meirleir K. A pediatric case definition for myalgic encephalomyelitis and chronic fatigue syndrome. J Chronic Fatigue Syndrome. 2006;13:1-44

6. Jelbert R, Stedmon J, Stephens A. A qualitative exploration of adolescents experiences of chronic fatigue syndrome. Clin Child Psychol Psychiatry. 2010;15:267-83.

7. Nijhof SL, Maijer K, Bleijenberg G, Uiterwaal CS, Kimpen JL, van de Putte EM. Adolescent chronic fatigue syndrome: prevalence, incidence, and morbidity. Pediatrics. 2011;127:e1169-75.

8. Bakken IJ, Tveito K, Gunnes N, Ghaderi S, Stoltenberg C, Trogstad L, Håberg SE, Magnus P. Two age peaks in the incidence of chronic fatigue syndrome/ myalgic encephalomyelitis: A population-based registry study from Norway 2008-2012. BMC Med. 2014:12

9. Naess H, Sundal E, Myhr KM, Nyland HI. Postinfectious and chronic fatigue syndromes: clinical experience from a tertiary-referral Centre in Norway. Vivo. 2010;24:185-8.

10. Garralda ME, Rangel L. Impairment and coping in children and adolescents with chronic fatigue syndrome: a comparative study with other paediatric disorders. J Child Psychol Psychiatry. 2004;45:543-52.

11. Taylor RR, O'Brien J, Kielhofner G, Lee SW, Katz B, Mears C. The occupational and quality of life consequences of chronic fatigue syndrome/myalgic encephalomyelitis in young people. Br J Occup Ther. 2010;73:524-30.

12. Sharpe M, Hawton $K$, Seagroatt V, Pasvol G. Follow up of patients presenting with fatigue to an infectious diseases clinic. BMJ. 1992:305:14752

13. Harris S, Gilbert M, Beasant L, Linney C, Broughton J, Crawley E. A qualitative investigation of eating difficulties in adolescents with chronic fatigue syndrome/myalgic encephalomyelitis. Clin Child Psychol Psychiatry. 2017;22: 128-39.

14. Varni JW, Burwinkle TM, Seid M, Skarr D. The PedsQL 4.0 as a pediatric population health measure: feasibility, reliability, and validity. Ambul Pediatr. 2003:3:329-41.

15. Varni JW, Burwinkle TM. The PedsQL as a patient-reported outcome in children and adolescents with attention-deficit/hyperactivity disorder: a population-based study. Health Qual Life Outcomes. 2006:4:26.

16. Winger A, Kvarstein G, Wyller VB, Ekstedt M, Sulheim D, Fagermoen E, Smastuen MC, Helseth S. Health related quality of life in adolescents with chronic fatigue syndrome: a cross-sectional study. Health Qual Life Outcomes. 2015:13:96.

17. Reinfjell T, Diseth TH, Veenstra M, Vikan A. Measuring health-related quality of life in young adolescents: reliability and validity in the Norwegian version of the Pediatric Quality of Life Inventory 4.0 (PedsQL) generic core scales. Health Qual Life Outcomes. 2006:4:61

18. Varni JW, Seid M, Kurtin PS. PedsQL 4.0: reliability and validity of the pediatric quality of life inventory version 4.0 generic core scales in healthy and patient populations. Med Care. 2001:39:800-12.

19. Hewlett S, Dures E, Almeida C. Measures of fatigue: Bristol Rheumatoid Arthritis Fatique Multi-Dimensional Questionnaire (BRAF MDQ), Bristol Rheumatoid Arthritis Fatigue Numerical Rating Scales (BRAF NRS) for severity, effect, and coping. Chalder Fatigue Questionnaire (CFO). Checklist Individual Strength (CIS20R and CIS8R), Fatigue Severity Scale (FSS), 
Functional Assessment Chronic Illness Therapy (Fatigue) (FACIT-F), MultiDimensional Assessment of Fatigue (MAF), Multi-Dimensional Fatigue Inventory (MFI), Pediatric Quality Of Life (PedsQL) Multi-Dimensional Fatigue Scale, Profile of Fatique (ProF), Short Form 36 Vitality Subscale (SF-36 VT), and Visual Analog Scales (VAS). Arthritis Care Res (Hoboken). 2011;63(Suppl 11):S263-86.

20. Sharp C, Goodyer IM, Croudace TJ. The short mood and feelings questionnaire (SMFQ): a unidimensional item response theory and categorical data factor analysis of self-report ratings from a community sample of 7-through 11-year-old children. J Abnorm Child Psychol. 2006;34: 379-91.

21. Kulis D, Bottomley A, Velikova G, Greimel E, Koller M, EORTC Quality of Life Group. EORTC quality of life study group translation procedure, 4th ED. Recource document. 2017. https://www.eortc.org/app/uploads/sites/2/2018/ 02/translation_manual 2017.pdf. Accessed 21.11.2019.

22. Jason L, Porter N, Shelleby E, Till L, Bell DS, Lapp CW, Rowe K, De Meirleir K. Severe versus moderate criteria for the new pediatric case definition for ME/ CFS. Child Psychiatry Hum Dev. 2009;40:609-20.

23. Fukuda K, Straus SE, Hickie I, Sharpe MC, Dobbins JG, Komaroff A. The chronic fatigue syndrome: a comprehensive approach to it's definition and study. Ann Intern Med. 1994;121:953-9.

24. Knight SJ, Harvey A, Hennel S, Lubitz K, Reveley C. Measuring quality of life and fatigue in adolescents with chronic fatigue syndrome: estimates of feasibility, internal consistency and parent- adolescent agreement of the PedsQLTM. Fatigue Biomed Health Behav. 2015;3.

25. Nijhof SL, Bleijenberg G, Uiterwaal CS, Kimpen $J$, van de Putte EM. Effectiveness of internet-based cognitive behavioural treatment for adolescents with chronic fatigue syndrome (FITNET): a randomised controlled trial. Lancet. 2012;379:1412-8.

26. Rowe KS. Long term follow up of young people with chronic fatigue syndrome attending a pediatric outpatient service. Front Pediatr. 2019;7:21.

27. Parslow R, Patel A, Beasant L, Haywood K, Johnson D, Crawley E. What matters to children with CFS/ME? A conceptual model as the first stage in developing a PROM. Arch Dis Child. 2015;100:1141-7.

28. Galeoto G, Sansoni J, Valenti D, Mollica R, Valente D, Parente M, Servadio A. The effect of physiotherapy on fatigue and physical functioning in chronic fatigue syndrome patients: a systematic review. Clin Ter. 2018;169:e184-8.

29. Richards J. Chronic fatigue syndrome in children and adolescents: a review article. Clin Child Psychol Psychiatr. 2000;5:31-51.

30. Deale A, Chalder T, Wessely S. Illness beliefs and treatment outcome in chronic fatigue syndrome. J Psychosom Res. 1998;45:77-83.

31. Lai JS, Stucky BD, Thissen D, Varni JW, DeWitt EM, Irwin DE, Yeatts KB, DeWalt DA. Development and psychometric properties of the PROMIS((R)) pediatric fatique item banks. Qual Life Res. 2013;22:2417-27.

32. Parslow RM, Harris S, Broughton J, Alattas A, Crawley E, Haywood K, Shaw A. Children's experiences of chronic fatigue syndrome/myalgic encephalomyelitis (CFS/ME): a systematic review and meta-ethnography of qualitative studies. BMJ Open. 2017:7:e012633.

33. Varni JW, Seid M, Rode CA. The PedsQL: measurement model for the pediatric quality of life inventory. Med Care. 1999;37:126-39.

\section{Publisher's Note}

Springer Nature remains neutral with regard to jurisdictional claims in published maps and institutional affiliations.

Ready to submit your research? Choose BMC and benefit from:
- fast, convenient online submission
- thorough peer review by experienced researchers in your field
- rapid publication on acceptance
- support for research data, including large and complex data types
- gold Open Access which fosters wider collaboration and increased citations
- maximum visibility for your research: over 100M website views per year
At BMC, research is always in progress.
Learn more biomedcentral.com/submissions

